\title{
Form and Content of the Diary of Heinrich Witt*
}

\author{
Christa Wetzel
}

\section{Volume 1}

\section{Binding}

Light brown leather, weak gold-colored edge lettering; gold-colored edge lettering on the book cover: EXTRACTS H.W.; on the spine: EXTRACTS H.W. VOL. I

\section{Paper}

Quarto, $245 \times 200$ mm, blanko.

\section{Script}

Ink, drawings also with pencil; corrections and additions in ink and pencil; underlinings and markings in pencil and ballpoint pen.

\section{Text pages}

pp. [o]-874; handwritten pagination, upper outer corner; pagination errors: pp. 624-629; p. 643 occurs twice; additional paper (strip) inserted and bound between p. 412 and 413 .

\section{Table of Contents}

7 pages without pagination [pp. 877-883]; complete.

\section{Appendices}

38 appendices mentioned in the existing text; extant are nos. 2-6 and 8-38, in addition the volume contains a letter by Witt's sister Maria (no number; inserted and bound between appendices nos. 19 and 18, bound today in this order).

\section{Secretaries involved}

Richard Bullen (to about p. 190), Andrew Garland (ca. pp. 190-369), George A. Coleman (pp. 370-874); according to the handwritings the Table of Contents was written by Bullen (p. 877), Garland (pp. 877-878) and a third person (pp. 878-883), possibly not Coleman.

\footnotetext{
* Translated from the German by Bill Templer.
} 


\section{Period of composition}

3 September 1859 to 4 March 1862 (pp. o-369), 30 September 1865 to early October 1867 (pp. 370-874). The Table of Contents for the first section seems to have been composed parallel to the text or shortly after; the Table of Contents for the second section was possibly written some years later.

\section{Damage/Text loss}

Body of the book undamaged; paper slightly discolored at the upper edge; some sheets slightly spotted; minimal text loss in the Table of Contents.

\section{Insertions in the $20^{\text {th }}$ century}

Volume was rebound anew; numerous underlinings and markings by pen, for example on María Sierra (pp. 100, 365, 6o6), Witt's activity for Daniel Schutte after the death of Anton von Lotten (pp. 111, 136), lines on the death of Anton von Lotten (pp. 127/128), on foreigners in Peru (pp. 102ff., 186f.), on Witt's description of Lima in 1827 (pp. 194ff.), description of a trip in Peru 1827 (near Cerro de Pasco, pp. 202ff.); in connection with the underlinings, corrections and markings penciled-in (for example, change of lower-case and capital lettering, correction of erroneous spellings, deletion of words), it is unclear when they were done; they were not taken into account for the transcription of this edition if they could not be associated with the handwriting of one of the secretaries.

\section{Content}

Vol. 1 consists of three parts. The first part (pp. 1-369) begins with a small amount of information about Witt, his life and family. Then the text continues with an account of 20 February 1824, the day Witt left London bound for South America. After the description of the journey across the Atlantic, there is an account of Witt's first years in Peru, which he spent initially in Arequipa, on trips to the coast and into the interior, and from 1833 on, his life in Lima, as office manager of the Gibbs, Crawley \& Co. trading company. The section ends with Witt's separation from the firm of Gibbs, Crawley \& Co in April 1842.

The second part (pp. 370-605) deals with Witt's childhood and youth in Altona, including his stay in the boarding school in Woodford Wells (1814-1815) in England and his period of apprenticeship and work as a clerk at the company of Conrad Hinrich Donner from 1816 on. It extends in describing Witt's life up to 1822 , ending shortly before Witt departed from Altona in January 1823 .

The third part (pp. 606-874) continues the description of Witt's life from April 1842. Along with Witt's life in Lima, the descriptions of trips into the north of Peru in 1842 and to Chile in 1842/43 are given significant space. The 
final entry in Vol. 1 describes the day 22 January 1843, when Witt, returning from Chile to Lima, made a side trip to Arequipa. (In the manuscript, instead of 1843 , the erroneous date 1867 is given, the year it was written.)

\section{Text form}

Preamble (pp. 1-6)

Diary (pp. 6-102, 112-116, 117-127, 128-135, 137-177, 178-181, 183-198, 200-298, 298301, 302-320, 320-324, 325-337, 338-350, 6o9-752, 799-874)

Connecting Narrative (pp. 102-111, 116f., 127f., 135-137, 177f., 181f., 199f., 298, 301f., 320, 324f., 337f., 350-369, 752-793)

Mixture of diary and report/connected description (pp. 370-605, 793-799)

Explanation (pp. 6o6-6o9).

\section{Volume 2}

\section{Binding}

Light brown leather, gold-colored edge lettering; gold-colored edge lettering on the book cover: EXTRACTS H.W., on the spine: EXTRACTS H.W. VOL. II

\section{Paper}

Quarto, $250 \times 200 \mathrm{~mm}$, blanko.

\section{Script}

In ink; corrections and additions in ink and pencil; underlinings and markings in pencil and ballpoint pen.

\section{Text pages}

pp. 2-896; pagination stamped in, upper outer corner; missing pages: pp. 160/161 (without any loss of text); additional paper (half sheet) inserted and bound between pp. 421 and 422 .

\section{Table of Contents}

12 pp., pagination stamped in, upper outer corner (pp. 897-9o8); complete.

\section{Appendices}

39 appendices mentioned in the existing text: nos. 1-38 and 12A; extant are nos. 1-11, 12A, 15-19, 32 and 38 ; in addition, the volume contains a slip (no number; loose insert). 


\section{Secretaries involved}

George A. Coleman (pp. 1-99), George Barker (pp. 99-305), George Graham (pp. 305-397), Charles Duval (pp. 397-896); according to the handwritings the Table of Contents was written by Graham (pp. 899-900), Duval (pp. 900-908) and a third person (pp. 897-898), possibly not Coleman.

\section{Period of composition}

9 October 1867 to the end of December 1869; the Table of Contents seems to have been written partly parallel to the section refereed to, partly later.

\section{Damage/Text loss}

Body of the book has fire damage; discolored and crumbling edges above and below, in places torn, loss of paper on the lower edges and lower outer corners; paper discolored at the edges, slightly spotted; small holes and tears in the sheets here and there; in some place, loss of text at the lower edge of page.

\section{Insertions from the $20^{\text {th }}$ century}

Volume was rebound anew; numerous underlinings and markings with ballpoint pen, for example in connection with passages concerning María Sierra Velarde (p. 3), political events in Peru (pp. 2off.), in "Connecting Narrative" from February to May 1843 (pp. 34ff.); it is unclear when the corrections and pencil markings were inserted, they were not taken into account in the transcription for this edition if they could not be associated with the handwriting of one of the secretaries.

\section{Content}

Vol. 2 begins with the continuation of Witt's stay in Arequipa from 24 January 1843 on and describes on the first 48 pages the months until 18 May 1843, when Witt departed on his 31-month trip to Europe, including the preparations for the trip and the goodbye visits that he made in Lima. Then the description of his trip to Europe begins, filling the remaining just under $85^{\circ} \mathrm{pp}$. of the volume. There are descriptions of the four-month ocean journey from Callao to London (pp. 48-99), Witt's stay in England, Ireland and Scotland in the following months (pp. 100-328), the time spent in Altona and the surrounding area from December 1843 to May 1844 (pp. 329-465), the trip through Holstein, Schleswig, Denmark, including an audience with the Danish king, on to Norway, then back to Altona, from May to August 1844 (pp. 466-642), the renewed stay in Altona including the trip to the Harz Mountains and Berlin (pp. 642-696) and finally the first part of Witt's 11-month extensive round trip from September 1844 to 
July 1845 . The text concludes with a description of 21 December 1844, when Witt was in Como in Italy after periods of stay in the Netherlands, Belgium, Germany and Switzerland.

Text form

Diary (pp. 2-30, 49-896)

Connecting Narrative (pp. 30-48)

Explanation (pp. 48f.).

\section{Volume 3}

\section{Binding}

Light brown leather, no edge lettering; gold-colored edge lettering on the book cover: EXTRACTS H.W., on the spine: EXTRACTS H.W. VOL. III

\section{Paper}

Quarto, $246 \times 201 \mathrm{~mm}$, blanko.

Script

In ink; corrections and additions in ink and pencil.

\section{Text pages}

pp. 2-887; pagination stamped in, upper outer corner; pagination errors: pp. 429/430 missing in pagination, instead 431/432 stamped in twice; missing pages: pp. 564/565, 618/619, 636/637, 772/773 and 804-807 (all without any loss of text); additional paper (with drawing) inserted and bound between pp. 143 and 144, supplementary sheet inserted and bound between pp. 585 and 586 , two additional sheets inserted and bound between pp. 739 and 740; on p. 182, two dried flowers pressed in.

\section{Table of Contents}

15 pages, pagination stamped in, upper outer corner (pp. 889-903); complete.

\section{Appendices}

28 appendices are mentioned in the existing text; extant are nos. 1-5 and 26-28.

\section{Secretaries involved}

Charles Duval (pp. 2-227), Thomas R. Rees (pp. 227-474), George A. Coleman (pp. 474-813), Victor Dupont (pp. 814-887); according to the handwritings the 
Table of Contents was written by Rees (pp. 889-892), a second person (pp. 892901), possibly not Coleman, and a later secretary, Edward Deeble (pp. 902-903).

\section{Period of composition}

29 December 1869 to mid-May 1872; the Table of Contents seems to have been written partly parallel to the section refereed to, partly later.

\section{Damage/Text loss}

Body of the book has fire damage and damage due to dampness; discolored and crumbling edges above and below, in some places torn; loss of paper on the lower edges and lower outer corners; paper discolored at the edges, slightly spotted; often there are (quite small) tears and holes in the paper; very frequent loss of text on the lower edge; in some places loss of page numbering.

\section{Insertions from the $20^{\text {th }}$ century}

Volume was rebound anew; it is unclear when the small number of corrections and signs using pencil were inserted; they were not taken into account in the transcription for this edition if they could not be associated with the handwriting of one of the secretaries.

\section{Content}

Like Vol. 2, Vol. 3 is also largely devoted to Witt's journey to Europe (pp. 2-640). The text begins with the continuation of the description of 21 December 1844 in Como. Then the further stages of the trip are described: from Italy via France and the Mediterranean to Algeria, once again back to France and then several months in Italy, finally the return journey via Austria and Germany on to Altona, where he arrived in mid-July 1845. After another seven weeks in Altona and Hamburg (pp. 519-567) and six weeks in England, where inter alia he visited William Gibbs at his country estate, Witt set off in mid-October on his return journey to Peru. The description of the trip from Southampton to Callao/Lima extends over another 87 pages in the volume (pp. 640-727). The remaining pages deal with Witt's time in Lima from 23 December 1845, including his trip to Arequipa in January and February 1846. The narrative stops within the entry for 30 August 1846.

\section{Text form}

Diary (pp. 2-813, 827-887)

Report (pp. 814-827). 


\section{Volume 4}

\section{Binding}

Light brown leather, no edge lettering; gold-colored edge lettering on the book cover: EXTRACTS H.W., on the spine: EXTRACTS H.W. VOL. IV

\section{Paper}

Quarto, 245 X $205 \mathrm{~mm}$, blanko.

\section{Script}

Ink; corrections and additions in ink and pencil.

\section{Text pages}

pp. 2-879; pagination stamped in, upper outer corner; missing pages: pp. 803/804 (without any loss of text).

\section{Table of Contents}

16 pages, pagination stamped in, upper outer corner (pp. 880-895); complete.

\section{Appendices}

9 appendices are mentioned in the existing text: nos. 1-8 and 10; non-extant is no. 4 .

\section{Secretaries involved}

Victor Dupont (pp. 2-342), Edward Deeble (pp. 342-879, Table of Contents).

\section{Period of composition}

22 May 1872 to ca. July/August 1874; the Table of Contents must have been included into the volume before 19 October 1874 (end of Edward Deeble's work as Witt's secretary).

\section{Damage/Text loss}

Body of the book has fire damage and damage due to dampness; discolored and crumbling edges above and below, in some places torn; loss of paper on the lower edges and lower outer corners; paper discolored at the edges, slightly spotted; there are some (quite small) tears and holes in the paper; loss of text on the lower side edge is almost continuous; in some places loss of page numbering. 


\section{Insertions in the $20^{\text {th }}$ century}

Volume was rebound anew; it is unclear when the small number of corrections and signs using pencil were inserted; they were not taken into account in the transcription for this edition if they could not be associated with the handwriting of one of the secretaries.

\section{Content}

Unlike the two previous volumes, Vol. 4 contains in the main descriptions of Witt's everyday life in Lima. The period described, from 30 August 1846 (the line of text entered under this date in Vol. 3 is repeated here) to 9 April 1851 (pp. 2-617), which Witt describes as a mixture of humdrum monotony and a series of smaller and larger celebrations, encompasses the first years of Witt's independent business activity, until his agreement with his son-in-law Christoph Wilhelm Schutte about the jointly owned trading firm Henry Witt \& Son in 1850/51 (later Henry Witt \& Schutte). This includes the marriage of his daughter Enriqueta von Lotten to the Englishman Gerald Garland in May 1848 and the birth of his first grandchild in November 1849, a grand ball in the house on Calle del Correo in October 1848, Witt's Latin lessons with his teacher Zyla and the first summer spent in Chorrillos. In August 1847, Witt began in addition to write an "account of my life" (pp. 121).

The second part of the volume (pp. 618-879) describes the first five months of Witt's next trip to Europe, a journey he took together with his wife and daughter Rosa Diez and her husband and daughters. The description of the trip extends from 9 April 1851 to 6 September 1851. After an extended stay in Paris and a side trip with Schutte to Altona and Hamburg, Witt was at this point in London, where along with the joint efforts to gain financial credits and orders for the firm Henry Witt \& Son, he also paid a number of visits to the Great Exhibition.

\section{Textform}

Diary.

\section{Volume 5}

\section{Binding}

Light brown leather, no edge lettering; gold-colored edge lettering on the book cover: EXTRACTS H.W., on the spine: EXTRACTS H.W. VOL. V 
Paper

Quarto, 240 x $200 \mathrm{~mm}$, blanko.

Script

Ink; corrections and additions in ink and pencil; vol. numbering "-Vol V-" in pencil (p. 31).

\section{Text pages}

pp. 31-876; handwritten pagination in the upper outer corner (in pencil to p. 59, in ink from p. 6o); the text of the sheet numbered in the manuscript pp. 47/48, in this edition is given at the beginning of the transcription ("page number unknown") due to an existing date entry that shows that the sheet had been erroneously inserted, numbered and bound.

\section{Table of Contents}

4 pages; pagination not extant [pp. 877-880]; incomplete, 7 September 1851 to 15/16 December 1851 .

\section{Appendices}

34 appendices mentioned in the existing text: nos. $2-13,13^{1 / 2}, 14,2 \times 15,16-28,2 \times$ 29, 30-32; not extant are nos. 2, 9, 10, 12, 31 and 32; in addition, there is a clipping from a newspaper (no number; inserted and bound between appendices nos. 11 and 13), two sections from newspaper clippings (no number; loose insert); appendix no. 8 is extant and contained in Vol. 6.

Secretaries involved

Edward Deeble (until p. 87), James Bryson (pp. 88-876, Table of Contents).

\section{Period of composition}

ca. July/August 1874 to after July 1876 ; the Table of Contents for 1860 was prepared in June 1876; it cannot be determined when the clean copy of the (entire) Table of Contents was included in the volume.

\section{Damage/Text loss}

Body of the book has serious fire damage and damage due to dampness; pages missing at the beginning of the volume; first sheets somewhat crumpled along the edges; discolored and crumbling edges above and below, in some places torn; clear loss of paper on the lower edges and corners; paper discolored at the edges; rarely (quite small) tears and holes on the lower page edge in the paper; 
loss of text almost continuous of at least one line on the lower edge of page; partial loss of page numbering.

\title{
Insertions from the $20^{\text {th }}$ century
}

Volume was rebound anew; Volume numbering "-Vol V-" (p. 31) and pagination of the pages at the beginning of the volume; incorrect ordering for one page; it is unclear when the small number of corrections and signs using pencil were inserted; they were not taken into account in the transcription for this edition if they could not be associated with the handwriting of one of the secretaries.

\section{Content}

Vol. 5 continues with the description of the trip to Europe in 1851/52. Even if the initial pages of the volume have not survived, we can learn from the extant part of the Table of Contents that the text continued on directly from the last entry in Vol. 4, describing the events of 7 September 1851. The stations of the trip after London were Brussels, a boat trip by Witt and María Sierra on the Rhine, several weeks in Hamburg and Altona, finally Paris once more and London again, where Witt was asked to appear in December 1851 in connection with the matter of a debt incurred by his son-in-law Schutte. The description of the trip, including the return journey from London to Peru, ends on p. 254. The following 67 pages describe Witt's life in Lima from the beginning of March $185^{2}$ to 28 October $185^{2}$, when Witt's eyesight had declined, worsening to a point where he could no longer read and write (pp. 254-321).

Following this, after a brief explanation dated 1 March 1875 regarding the break in the chronology of the life history (pp. 321f.) arising from his eye disease, the description of Witt's life from 10 June 1856 is resumed. That was the day Witt and his spouse returned to Lima from their next trip to Europe (1854-1856). The description of the following years in Witt's life concludes with the entry for $3^{1}$ December 1861 (pp. 322-876). The time period described encompasses Witt's last trip to Arequipa from 28 March to 10 May 1859 (pp. 553-587), and the contract of October 1860 concluded between the Peruvian government and the firm of Henry Witt \& Schutte for the export of guano to Germany and the Baltic countries from January 1862 on (pp. 745 ff.).

\author{
Text form \\ Diary (until pp. 321, 462-876) \\ Explanation (pp. 321f.) \\ Report (pp. 322-462).
}




\section{Volume 6}

\section{Binding}

Light brown leather, no edge lettering; gold-colored edge lettering on the book cover: EXTRACTS H.W., on the spine: EXTRACTS H.W. VOL. VI

\section{Paper}

Quarto, $243 \times 208 \mathrm{~mm}$, blanko.

\section{Script}

Ink; corrections and additions in ink and pencil.

\section{Text pages}

pp. 1-863; pagination stamped in, upper outer corner; pp. 667/668 no text written.

\section{Table of Contents}

16 pages (pp. 866-881); pagination stamped in, upper outer corner; incomplete, 28 October 1852 to 10 June 1856 , 1 January 1862 to 20 May 1863.

\section{Appendices}

21 appendices mentioned in the existing text; extant are nos. 10-21 and no. 22 with reference to the non-extant p. 865; in addition, there is a section of a newspaper clipping with the heading "8 page 161" (belonging to Vol. 5).

Secretaries involved

James Bryson (including the Table of Contents).

\section{Period of composition}

29 November 1875 to ca. mid-October 1877; the Table of Contents for 1855 was prepared in November 1876 , for 1867 in October 1877 , the clean copy was inserted in the volume in February 1879.

\section{Damage/Text loss}

Body of the book has serious fire damage and damage due to dampness; discolored and crumbling edges above and below, in some places torn; clear loss of paper on the lower edges and corners; paper discolored and spotted extending in from the edges; loss of text almost continuous of (at least) one line on the lower edge of page; partial loss of page numbering. 


\section{Insertions from the $20^{\text {th }}$ century}

The volume was bound anew; it is unclear when the small number of corrections and signs using pencil were inserted; they were not taken into account in the transcription for this edition if they could not be associated with the handwriting of one of the secretaries.

\section{Content}

Volume 6 begins with the description, announced in Vol. 5 for a later point in time, of the period excluded there from the end of October $185^{2}$ to 10 June 1856 (pp. 1-285). This period in Witt's life includes initially ca. two years in Lima, in the description of which the effects of his eye disease take up considerable space. On 11 August 1854, Witt commenced his next trip to Europe. Together with María Sierra he traveled via New York to England, and from there on the the continent. Stations along the journey were Brussels, Hamburg and Altona, and Berlin, where Witt at the beginning of 1855 spent several weeks in a medical clinic for treatment of his eye disease, and finally Paris. In the summer of 1855 , the married couple undertook a five-month trip to southern Europe with their granddaughters Conradina and Amalia Schutte Diez, who in 1851 had stayed in Hamburg for purposes of their further education. The first part of Vol. 6 ends with the return to Lima in June 1856 .

Subsequent to this, the account of Witt's life in Lima continues from 1 January 1862, taking up the thread again from the end of Vol. 5 . The following roughly 90 pages describe the 13 months until the end of January 1863 , when Witt departed once more for Europe, to where María Sierra and Enriqueta von Lotten had already journeyed the previous August. The description of the journey from 29 January to 15 September 1863, with stays inter alia in England, Hamburg and Berlin, but mainly in Paris and Vichy, comprises more than 170 pages (pp. 377-550). The remaining pages in the volume contain a description of Witt's life in Lima over the subsequent $4 \frac{1}{2}$ years. This period contains, for example, the purchase of the house on Calle de Zárate (1864) and the law suits associated with this, the wars surrounding the duchies of Schleswig and Holstein $(1864,1866)$, carefully followed by Witt, and his increasing engagement as a shareholder and director of the banks and other corporate enterprises being established in Lima.

The last extant entry (p. 863) describes the day of 6 March 1868, a short time after the dissolving of the firm Henry Witt \& Schutte. Since it is noted in the extant appendix no. 22, in the copy of a letter from the then finance minister José Luis Gomez Sanchez to Schutte y Cia, dated 13 March 1868, that this belongs with p. 865 , it can be assumed that the pages $864 / 865$, today missing, were written on with text. The fact that Vol. 7 begins with the description of 20 March 1868 also suggests that this was probably the case. 


\section{Text form}

Explanation (p. 1)

Report (pp. 2-34, 282-285)

Diary (pp. 34-281, 286-863).

\section{Volume 7}

\section{Binding}

Light brown leather, no edge lettering; gold-colored edge lettering on the book cover: EXTRACTS H.W., on the spine: EXTRACTS H.W. VOL. VII

\section{Paper}

Quarto, $249 \times 211 \mathrm{~mm}$, blanko.

\section{Script}

Ink; corrections and additions in ink and pencil.

Text pages

pp. 1-877; pagination stamped in, upper outer corner; sheet inserted and bound between pp. 85 and 86 .

\section{Table of Contents}

27 pages (pp. 878-904); pagination stamped in, upper outer corner; partially in the form of special thematic headings within the chronological sequence; incomplete, 20 March 1868 to 18 January 1876.

\section{Appendices}

22 appendices are mentioned in the existing text; all appendices are extant; in addition, the volume contains a small section of a newspaper clipping (no number, loose insert).

Secretaries involved

James Bryson (including Table of Contents).

Period of composition

27 October 1877 to ca. mid-February 1879; the Table of Contents was prepared in 1878 and 1879; when the clean copy was inserted in the volume cannot be determined. 


\section{Damage/Text loss}

Body of the book has fire damage and damage due to dampness; discolored and crumbling edges above and below, in some places torn; clear loss of paper on the lower edges and corners; paper discolored and spotted extending in from the edges, particularly at the beginning of the volume; paper in some places curled; loss of text almost continuous of (at least) one line on the lower edge of page; partial loss of page numbering.

\section{Insertions from the $20^{\text {th }}$ century}

The volume was bound anew; it is unclear when the small number of corrections and signs using pencil were inserted; they were not taken into account in the transcription for this edition if they could not be associated with the handwriting of one of the secretaries.

\section{Content}

Vol. 7 is the first volume in Heinrich Witt's diary that does not contain the description of a trip. The text describes Witt's life in Lima from 20 March 1868 to 20 January 1876 . This period includes inter alia the yellow fever epidemic in Lima and Callao in the first half of 1868 and the powerful earthquake of 13 August 1868, the Franco-German War 1870/71, which Witt followed in newspapers and correspondence, and the revolution in France in 1871. In Lima he observed the progress in changes in urban development, such as the demolition of the city wall, the construction of the Palacio de la Exposición and, over and beyond the capital, the construction of the railroad, in which he was also financially involved. As in all the volumes, the political and economic developments in Peru take up significant space, including the Dreyfus Treaty (1869) and the dispute between the banks and the government under the first civilian president of Peru, Manuel Pardo. Witt's activities in the corporate enterprises are repeatedly described in some detail. Important themes in Witt's family life in this period were the move to the house on Calle de Zárate (1871), followed by new legal suits, and María Sierra's declining health.

In the Table of Contents for Vol. 7 , there are for the first time special thematic headings within the chronological sequence, in which the corresponding entries are grouped together by year, for example, "Meetings of the Directors and Shareholders of," "Deaths," "Marriages," "Lawsuit with Leyva, about Ayres of his house."

\section{Textform}

Diary. 


\section{Volume 8}

\section{Binding}

Light brown leather, no edge lettering; gold-colored edge lettering on the book cover: EXTRACTS H.W., on the spine: EXTRACTS H.W. VOL. VIII

\section{Paper}

Quarto, $242 \times 213 \mathrm{~mm}$, blanko, some sheets bear the watermark Whatman 1877 .

\section{Script}

Ink; corrections and additions in ink and pencil.

\section{Text pages}

pp. 1-875; pagination stamped in, outer upper corner, on the first 100 pages not extant, thereafter in part discernible; additional paper inserted and bound between pp. 547 and 548, additional sheet inserted and bound between pp. 783 and 784 .

\section{Table of Contents}

26 pages (pp. 876-901); pagination stamped in, outer upper corner, only partially discernible; in part in the form of special thematic headings within the chronological sequence; complete.

\section{Appendices}

48 appendices are mentioned in the existing text: nos. 1, 2, 2 $\times 3,4-25,2 \times 26$, 27-46; extant are the appendices nos. 1, 2, 6, 7 and 9 .

\section{Secretaries involved}

James Bryson (pp. 1-617), Neat Ladd (pp. 618-875, Table of Contents).

\section{Period of composition}

22 February 1879 until approximately mid-April 1880; the Table of Contents was prepared in 1880; when the clean copy was inserted in the volume cannot be determined.

\section{Damage/Text loss}

Body of the book has significant fire damage and damage due to dampness; discolored and crumbling edges above and below, in some places torn; clear loss of paper on the upper edges and corners; paper in part heavily discolored and spotted; loss of text almost continuous of (at least) one line of text on the 
upper edge of the page; frequent loss of text on the lower edge of the page; nearly continuous loss of page numbering.

\section{Insertions from the $20^{\text {th }}$ century}

Volume was rebound anew; it is unclear when the small number of corrections and signs using pencil were inserted; they were not taken into account in the transcription for this edition if they could not be associated with the handwriting of Neat Ladd.

\section{Content}

Vol. 8 describes Witt's life in Lima from 21 January 1876 to 12 March 1879. The most important event for Heinrich Witt during this period was doubtless the death of his wife on 20 May 1876 (pp. 101ff.). Initially concern and worry, then mourning and memories, determination and distribution of the estate of María Sierra, construction of the mausoleum in the cemetery and Witt's visits there are recurrent topics in the description of these three years. But alongside this, as in the previous volumes, Witt's business and social activities are dealt with in part in very detailed fashion, including a further legal suit in connection with the house on Calle de Zárate.

Important topics in regard to Peru are the continuing economic crisis, the murder of Manuel Pardo in November 1878 (pp. $788 \mathrm{ff}$.) and the harbingers of the War of the Pacific with Chile (1879-83). The Table of Contents for this volume, which retains the special thematic headings introduced in Vol. 7 , has correspondingly a special heading for the year 1879 "Events of the Perú-BoliviaChilian War" (p. 90o).

In Vol. 8, there is also regular mention of the work with James Bryson on the diary in the description of Witt's daily life. In addition to his further extensive and diverse reading fare, noted in the diary, Witt in 1877 also asked Bryson to read passages aloud to him from the first volume of the diary (p. 507).

Textform

Diary.

\section{Volume 9}

\section{Binding}

Light brown leather, no edge lettering; gold-colored edge lettering on the book cover: EXTRACTS H.W., on the spine: EXTRACTS H.W. VOL. IX 
Paper

Quarto, $252 \times 206 \mathrm{~mm}$, blanko, sheets in part with the watermark J Whatman 1879.

Script

Ink; corrections and additions in ink and pencil.

Text pages

pp. 1-871; pagination stamped in, upper outer corner.

\section{Table of Contents}

28 pages (pp. 872-899); pagination stamped in, upper outer corner; partially in the form of special thematic headings within the chronological sequence; complete.

\section{Appendices}

25 appendices are mentioned in the existing text; not extant are nos. 3 and 20; in addition, there is an extant newspaper clipping (no number, loose insert).

Secretaries involved

Neat Ladd (including Table of Contents).

Period of composition

26 April 1880 to middle/end of May 1881 (including the Table of Contents).

Damage/Text loss

Body of the book has fire damage and damage due to dampness; discolored and crumbling edges above and below, in some places torn; loss of paper on the lower edges and at corners; paper in part spotted extending in from the edges; frequent loss of text on the lower edge of the page.

Insertions from the $20^{\text {th }}$ century

Volume was rebound anew; it is unclear when the small number of corrections and signs using pencil were inserted; they were not taken into account in the transcription for this edition if they could not be associated with the handwriting of Neat Ladd.

\section{Content}

Vol. 9 describes on the one hand the time from 13 March 1879 to 16 May 1881; on the other, the volume contains a description missing in Witt's life history up until then, namely an account of the time from 1 January 1823 , when he left Altona and departed on his first trip through Europe, and then going to 
London, until 20 February 1824, the day with which the text in Vol. 1 begins. In order to include the description, 235 pages in length, of the ca. 12 months from 1823/4 (pp. 456-69o), the description of Witt's life in 1880 was interrupted after 30 September. Important topics in this volume, along with the description of the trip lying more than $5^{0}$ years in the past, is the continuing mourning and sadness around the death of María Sierra, the War of the Pacific, the revolution of Nicolás de Piérola in December 1879 and the following dictatorship of the "Supreme Chief," and the occupation of Lima from January 1881 (pp. $782 \mathrm{ff}$.).

In this volume, for the first time in Witt's diary, the time described and the time of composition fall together. The compositional present was initially reached at the end of September 1880 (p. 447). After concluding the description of the trip 1823/24, Witt and Ladd were again up to date with the clean copy around mid-April 1881 (p. 848). For that reason, it can be assumed that the final date in terms of content in the volume corresponds more or less to the final time of composition of the volume. Afterward the Table of Contents was then prepared and included in the volume. As in the two preceding volumes, special thematic headings are noted in the Table of Contents.

Text form

Diary.

\section{Volume 10}

\section{Binding}

Light brown leather, no edge lettering; gold-colored edge lettering on the book cover: EXTRACTS H.W., on the spine: EXTRACTS H.W. VOL. X

\section{Paper}

Quarto, $251 \times 212 \mathrm{~mm}$, blanko.

\section{Script}

Ink; volume numbering "Vol X" in pencil (p. 22).

\section{Text pages}

pp. 22-581; pagination stamped in, upper outer corner; pages 154-157 missing (with text loss 23 to 30 May 1887); additional sheet inserted and bound between pp. 293 and 294.

\section{Table of Contents}

Not extant. 


\section{Appendices}

29 appendices are mentioned in the existing text: nos. 1-24, 26-28 and $45^{2}$ (sic) as well as one appendix mentioned with number lost due to text loss (p. 462); no appendices extant.

Secretaries involved

Neat Ladd.

Period of composition

19 January 1887 to at least 30 December 1890.

\section{Damage/Text loss}

Body of the book has in part serious fire damage and damage due to dampness; pages are missing at the beginning of the volume; some sheets at the volume's beginning are crumpled; discolored and crumbling edges above and below; loss of paper on the lower edges and at corners; paper in part spotted extending in from the edges; rarely there are (smaller) tears and holes in the paper; loss of text on the lower edge of the page.

Insertions from the $20^{\text {th }}$ century

Volume was rebound anew; volume numbering: "Vol X" (p. 22).

\section{Content}

The $10^{\text {th }}$ extant volume, originally Vol. 13 of Witt's diary, describes his life in Lima (and Chorrillos) from the end of October $1886 \mathrm{on}$. The first day dated is 29 October (p. 23). The last extant entry is an account of 29 December 1890 (p. 581), whose description remains incomplete.

In the description of Witt's life in his much later years, private topics predominate, even if there is continued discussion of political, economic and social events in Peru and Europe. Recurrent topics are family life in the house on Calle de Zárate with his daughter, son-in-law, grandchildren and greatgrandchildren, the construction of the new rancho in Chorrillos (including documentation of Witt's expenses for the house) and the stays there in the summer months, and finally Witt's increasing physical debility. Witt's unchanged multifarious avid reading in several languages is also noted in the diary.

Text form

Diary. 